\title{
A multi-period distribution network design model under demand uncertainty
}

\author{
Babak H Tabrizi and Jafar Razmi
}

\begin{abstract}
Supply chain management is taken into account as an inseparable component in satisfying customers' requirements. This paper deals with the distribution network design (DND) problem which is a critical issue in achieving supply chain accomplishments. A capable DND can guarantee the success of the entire network performance. However, there are many factors that can cause fluctuations in input data determining market treatment, with respect to short-term planning, on the one hand. On the other hand, network performance may be threatened by the changes that take place within practicing periods, with respect to long-term planning. Thus, in order to bring both kinds of changes under control, we considered a new multi-period, multi-commodity, multi-source DND problem in circumstances where the network encounters uncertain demands. The fuzzy logic is applied here as an efficient tool for controlling the potential customers' demand risk. The defuzzifying framework leads the practitioners and decision-makers to interact with the solution procedure continuously. The fuzzy model is then validated by a sensitivity analysis test, and a typical problem is solved in order to illustrate the implementation steps. Finally, the formulation is tested by some different-sized problems to show its total performance.
\end{abstract}

Keywords: Supply chain, Distribution network design, Uncertain demand, Fuzzy logic

\section{Introduction}

Moving towards competitive markets compels the manufacturers to increase their qualifications so that they can best fulfill the customers' needs. The supply chain management (SCM) concept arose as an effective managerial tool to enhance the customers' satisfaction within the last 20 years in particular (Azaron et al. 2008; Jayaraman and Ross 2003). Generally, a supply chain (SC) can be defined as a set of plants, distribution centers, and customers in which the products are completed once they are transmitted downstream the chain and delivered to the customers (Altiparmak et al. 2006; Blackhurst et al. 2004).

Distribution network design (DND) is one of the primitive principles in establishing a successful SC. It is associated with the category of production-distribution and facility location-allocation problems (Altiparmak et al. 2009). The researchers investigate the distribution networks under two distinctive categories including strategic and tactical levels. The first level concerns with

\footnotetext{
* Correspondence: babaktabrizi@ut.ac.ir

Department of Industrial Engineering, Faculty of Engineering, University of Tehran, P.O. Box: 11155-4563, Tehran, Iran
}

whatever affects the entire network configuration (e.g., the numbers, capacities, and locations), and the second level deals with whatever affects the aggregate quantities (e.g., material handling, processing, and distribution) (Santoso et al. 2005). Consequently, considering the two planning levels simultaneously is very fruitful in enhancing the network performance.

A DND problem can also incorporate five aspects according to the necessity (please refer to Tang (2006) for more description):

- Network configuration (NC)

- Product assignment (PA)

- Customer assignment (CA)

- Production planning (PP)

- Transportation planning (TP)

Regarding the above, the proposed model covers the first four aspects at the same time.

Some other issues are expected in the model structure likewise (e.g., the number of consideration periods, sources, echelons, and commodities). For example, Amiri (2006) suggested a multi-capacity distribution 
network in deterministic environments so that both strategic and tactical levels were included. Gupta and Maranas (2003) concentrated on the tactical level in a multicommodity, multi-echelon, multi-period problem. The authors considered demand as the uncertain parameter. Selim and Ozkarahan (2006) developed a fuzzy multi-echelon, multi-commodity, multi-capacity problem by considering both levels. They introduced the demand as the uncertain part likewise. Liu et al. (2006) introduced a multi-commodity DND problem and dealt with the potential uncertainties by the combination of gray and fuzzy factors. Azaron et al. (2008) proposed a multi-commodity, multi-source model and solved it by the goal attainment technique. However, they extended the uncertainty and vagueness to all three demand-, supply-, and process-side risks. Gumus et al. (2009) applied a neuro-fuzzy technique for demand uncertainty in a multi-echelon condition. $\mathrm{Xu}$ et al. (2009) developed a multi-echelon, multi-source problem where the demand, supply, and process follow a fuzzy nature. They applied a heuristic solution approach called spanning tree technique that originated from genetic algorithm. Peidro et al. (2010) proposed a multi-echelon, multi-period, multi-commodity, multi-source mathematical modeling under fuzzy programming so that all three mentioned sides were uncertain. Compared with the mentioned researches, our developed model lies in a three-echelon, multi-source, multi-period, multi-commodity, singlecapacity category in which the two levels are planned. The environment under consideration faces a demand-side risk which is tackled with by the fuzzy mathematical modeling. A brief overview on DND literature is depicted in Table 1.

The rest of the paper is organized as follows: model formulation is presented in the next section. Solution methodology is described in the third section, which also demonstrates how the fuzzy steps can be implemented. The fourth section pertains to the computational study, and finally, the conclusions and future research interests are discussed in the 'Conclusions' section.

\section{Model formulation}

In this section, the mixed-integer mathematical model is defined and the fuzzy approach is described. Before we construct the mathematical formulation, the assumptions, indices, parameters, and decision variables are introduced as follows:

\section{Assumptions}

- Demand parameter follows a fuzzy nature.

- A given plant or distributor can be open or close in each horizon.

- The number of practicing facilities cannot exceed the predefined upper bound.
- The processing capacity of each plant and distributor is known with respect to the commodities.

- The facility capacity is fixed during the total horizon periods.

- Each tier can supply its needs from more than one member of the upper tier.

2. Indices

- $C$ : set of commodities $(c \in C)$

- $P$ : set of plants $(p \in P)$

- $J$ : set of distributors $(j \in J)$

- I: set of customers $(i \in I)$

- $H$ : set of planning horizons $(h \in H)$

3. Parameters

- $\mathrm{FC}_{p h}$ : annual fixed cost of plant $p$ in period $h$

- $\mathrm{FC}_{j h}^{\prime}$ : annual fixed cost of distributor $j$ in period $h$

- $\mathrm{LC}_{p c h}$ : logistics cost for supplying commodity $c$ in period $h$ from plant $p$ to distributor $j$

- $\mathrm{LC}^{\prime}{ }_{\text {jchi: }}$ : logistics cost for supplying commodity $c$ in period $h$ from distributor $j$ to customer $i$

- $d_{i c h}$ : demand of customer $i$ for commodity $c$ in period $h$

- $\alpha_{p c}$ : capacity of plant $p$ for commodity $c$

- $\alpha_{j c}^{\prime}$ : capacity of distributor $j$ for commodity $c$

- $P_{\text {Upper: }}$ the upper bound for the number of open plants

- $J_{\text {Upper: }}$ : the upper bound for the number of open distributors

4. Decision variables

- $x_{p c h j}$ : the proportion of commodity $c$ in period $h$ transported from plant $p$ to distributor $j$

- $y_{j c h i}$ : the proportion of commodity $c$ in period $h$ transported from distributor $j$ to customer $i$

- $Z_{p h}$ : the binary variable that takes 1 if plant $p$ is open in period $h$ and 0 , otherwise

- $Z_{j h}^{\prime}$ : the binary variable that takes 1 if distributor $j$ is open in period $h$ and 0 , otherwise

- $\mathrm{LQ}_{c h j}$ : the left quantity of commodity $c$ in period $h$ for distributor $j$

Now, the model can be developed by Equations 1 to 8 , as follows:

$$
\begin{aligned}
\operatorname{Min}= & \sum_{p=1}^{P} \sum_{c=1}^{C} \sum_{h=1}^{H} \sum_{j=1}^{J} \sum_{j=1}^{C} \sum_{c=1}^{H} \sum_{h=1}^{I} \mathrm{LC}_{j=1}^{\prime} \mathrm{x}_{j c h i} y_{j c h i} d_{j i c h}^{\prime}+ \\
& \sum_{p=1}^{P} \sum_{h=1}^{H} \mathrm{FC}_{p h} Z_{p h}+\sum_{j=1}^{J} \sum_{h=1}^{H} \mathrm{FC}_{j h}^{\prime} Z_{j h}^{\prime}
\end{aligned}
$$




\begin{tabular}{|c|c|c|c|c|c|c|c|c|c|c|c|c|c|}
\hline \multirow[t]{2}{*}{ Articles } & \multicolumn{5}{|c|}{ Aspects } & \multicolumn{5}{|c|}{ Features } & \multirow[t]{2}{*}{ Nature } & \multirow[t]{2}{*}{ Uncertain parameter(s) } & \multirow[t]{2}{*}{ Solution approach } \\
\hline & NC & PA & CA & PP & TP & Product & Stage & Period & Source & Capacity & & & \\
\hline Jayaraman and Ross (2003) & $* * *$ & $* * *$ & $* * *$ & & & Multiple & Three & Single & Single & Single & Deterministic & - & Simulated annealing \\
\hline Santoso et al. (2005) & $* * *$ & $* * *$ & $* * *$ & $* * *$ & & Multiple & Two & Single & Multiple & Single & Stochastic & Demand, supply, and process & $\begin{array}{l}\text { Sample average approximation scheme } \\
\text { and accelerated Benders' decomposition }\end{array}$ \\
\hline Altiparmak et al. (2006) & $* * *$ & & $* * *$ & $* * *$ & & Single & Multiple & Single & Single & Single & Deterministic & - & Genetic algorithm \\
\hline Selim and Ozkarahan (2006) & $* * *$ & $* * *$ & & *** & & Multiple & Three & Single & Single & Multiple & Fuzzy & Demand & Fuzzy multi-objective programming \\
\hline Goh et al. (2007) & $* * *$ & & $* * *$ & & & Single & Two & Single & Multiple & Single & Stochastic & Demand and supply & Heuristic algorithm \\
\hline Chen et al. (2007) & & *** & $* * *$ & $* * *$ & & Multiple & Three & Multiple & Multiple & Single & Fuzzy & Demand & Fuzzy programming \\
\hline You and Grossmann (2008) & $* * *$ & $* * *$ & & $* * *$ & & Multiple & Multiple & Multiple & Single & Single & Probabilistic & Demand & $\varepsilon$-Constraint \\
\hline Cakir (2009) & $* * *$ & $* * *$ & & $* * *$ & $* * *$ & Multiple & Two & Single & Multiple & Single & Deterministic & - & Benders' decomposition \\
\hline Altiparmak et al. (2009) & $* * *$ & $* * *$ & $* * *$ & $* * *$ & & Multiple & Multiple & Single & Single & Single & Deterministic & - & Genetic algorithm \\
\hline Georgiadis et al. (2011) & $* * *$ & $* * *$ & $* * *$ & *** & & Multiple & Three & Single & Multiple & Single & Stochastic & Demand & Branch-and-bound \\
\hline Cintron et al. (2010) & $* * *$ & & $* * *$ & & & Single & Three & Single & Single & Multiple & Stochastic & Demand & Goal programming \\
\hline Hajiaghaei-Keshteli (2011) & $* * *$ & & $* * *$ & & & Single & Two & Single & Multiple & Single & Deterministic & - & $\begin{array}{l}\text { Genetic algorithm and artificial immune } \\
\text { algorithm }\end{array}$ \\
\hline Cardona-Valdes et al. (2011) & $* * *$ & & $* * *$ & $* * *$ & $* * *$ & Single & Three & Single & Multiple & Single & Stochastic & Demand & L-shaped algorithm \\
\hline Rezapour and Farahani (2010) & $* * *$ & & $* * *$ & & & Single & Three & Single & Multiple & Multiple & Deterministic & - & A modified projection method \\
\hline Park et al. (2010) & $* * *$ & & $* * *$ & & & Single & Three & Single & Single & Single & Deterministic & - & A two-phase heuristic algorithm \\
\hline Our proposed model & $* * *$ & $* * *$ & $* * *$ & $* * *$ & & Multiple & Three & Multiple & Multiple & Single & Fuzzy & Demand, supply, and process & Fuzzy programming \\
\hline
\end{tabular}


S.t.:

$$
\begin{aligned}
& \sum_{j-1}^{J} y_{j c h i} \leq 1 \quad ; \forall i, c, h \\
& \sum_{j-1}^{J} x_{p c h j} a_{j c}^{\prime} \leq Z_{p h} a_{p c} \quad ; \forall p, h, c \\
& \mathrm{LQ}_{c h j}=\sum_{p=1}^{P} x_{p c h j} a_{j c}^{\prime}-\sum_{i=1}^{I} y_{j c h i} d_{i c h}+\mathrm{LQ}_{c(h-1) j} \quad ; \forall c, h, j \\
& \sum_{i=1}^{I} y_{j c h i} d_{i c h} \leq \mathrm{LQ} \mathrm{Q}_{c h j} \leq Z_{j h}^{\prime} a_{j c}^{\prime} \quad ; \forall j, c, h \\
& \sum_{p=1}^{P} Z_{p h}=P_{\mathrm{Upper}} \quad ; \forall h \\
& \sum_{j=1}^{J} Z_{j h}^{\prime}=J_{\mathrm{Upper}} \quad ; \forall h \\
& Z_{p h}, Z_{j h}^{\prime} \in\{0.1\}, \quad 0 \leq x_{p c h j}, y_{j c h i} \leq 1 .
\end{aligned}
$$

Considering the presented formulation, Equation 1 is the objective function (OF) which consisted of logistic and annual fixed costs. In other words, the first two parts deal with the total sum of logistic costs (i.e., variable costs including processing, transportation, etc.). It is calculated for both the practicing plants and distributors separately. This type of cost is obtained from the commodity volume multiplied by the associated capacity. For example, the logistic cost of plants is determined by the corresponding unit logistic cost, to supply a given commodity from a plant to a distributor in a specific period, multiplied by the satisfied quantities. The values of responded needs are obtained from the multiplication of the given capacity by the satisfied proportion. The same calculations can be presented for distributors likewise. Furthermore, the fixed cost is realized for each of the plants and distributors with respect to the extant cost once the facility is practicing in the corresponding period. Equation 2 shows the fraction of satisfied demands for each of the commodities in each planning horizon with respect to the existing customers. However, a potential customer can acquire its demanded commodities from a set of distributors instead of focusing on a single one. Equation 3 guarantees that the transportation quantity from plants to distributors cannot surpass the given plant capacity, if it is open in the mentioned period. Equation 4 denotes that the left quantity for each commodity and distributor in each period can be calculated by the sum of transported quantities to customers subtracted from the sum of transported quantities to a distributor added to the left quantity in the previous period. Equation 5 is the same as Equation 3 but concerns the distributors and affirms that the output of each distribution center does not exceed its extant capacity, restricted by the remaining commodities. Moreover, the volume of the left commodities cannot exceed the distributor capacity. Equations 6 and 7 state that the number of open plants and distribution centers in each of the planning horizons should not exceed their upper bounds (i.e., the maximum allowed numbers), respectively. Furthermore, Equation 8 deals with the nature of existing variables.

The schematic performance of our multi-commodity, multi-period, multi-source network is depicted in Figure 1 for a given planning horizon.

\section{Solution methodology}

Since we presumed that the developed distribution network practices in a vague environment, demand uncertainty can be represented by fuzzy numbers efficiently. In order to solve the model, we applied the fuzzy approach

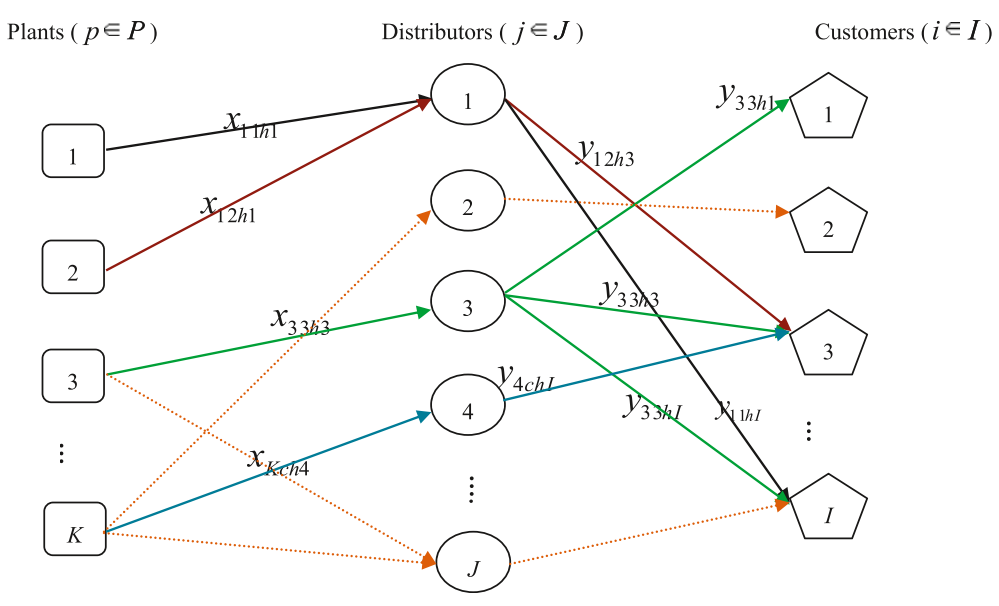

Figure 1 The proposed three-stage distribution network performance in period $\mathrm{h}$. 
suggested by Jimenez et al. (2007) which consists of a three-phase interaction algorithm.

\section{Converting the fuzzy model into its crisp equivalent}

In this section, we show the main framework of the implementation method of fuzzy approach proposed by Jimenez et al. (2007). Regarding the risk threatening estimated demands, all OF coefficients, technological multipliers, and right-hand side coefficients may take a vague quantity. For instance, consider the following problem in which $\tilde{C}^{\prime}=\left(\tilde{c}_{1}^{\prime}, \tilde{c}_{2}^{\prime}, \ldots \tilde{c}_{n}^{\prime}\right), \tilde{A}^{\prime \prime}=\left[\tilde{a}_{i j}^{\prime \prime}\right]_{m \times n}$, and $\tilde{B}^{\prime}=\left(\tilde{b}_{1}^{\prime}, \tilde{b}^{\prime}, \ldots \tilde{b}_{m}^{\prime}\right)^{t}$ are the fuzzy parameters representing the OF coefficients, technological multiplies, and righthand side coefficients, respectively. Therefore, the fuzzy mathematical model can be represented by Equation 9:

$$
\begin{aligned}
& \operatorname{Min}=\tilde{C}^{\prime t} x \\
& \text { S.t. }: \tilde{A}^{\prime \prime} x \geq \tilde{B}_{i}^{\prime} \\
& x \in R^{n}, \geq 0 .
\end{aligned}
$$

The uncertainty in the nature of fuzzy problems makes the decision-makers (DMs) find a solution so that both feasibility and optimality conditions can be satisfied efficiently. Consequently, there has been a great effort on determining different methods which could fulfill the two above characteristics (e.g., refer to Rommelfanger and Slowinski (1998)). Some papers have also discussed the ranking methods besides their justifications. We applied the method introduced by Jimenez (1996) to our problem.

It is assumed that the applied fuzzy parameters follow a trapezoidal nature in order to provide a broader range of potential values. Figure 2 shows the trapezoidal fuzzy number $n$, in which the $\alpha$-cut equals the feasibility degree for a specific decision.

Considering the above definitions, the corresponding parts of the OF and constraints (i.e., the parts that include

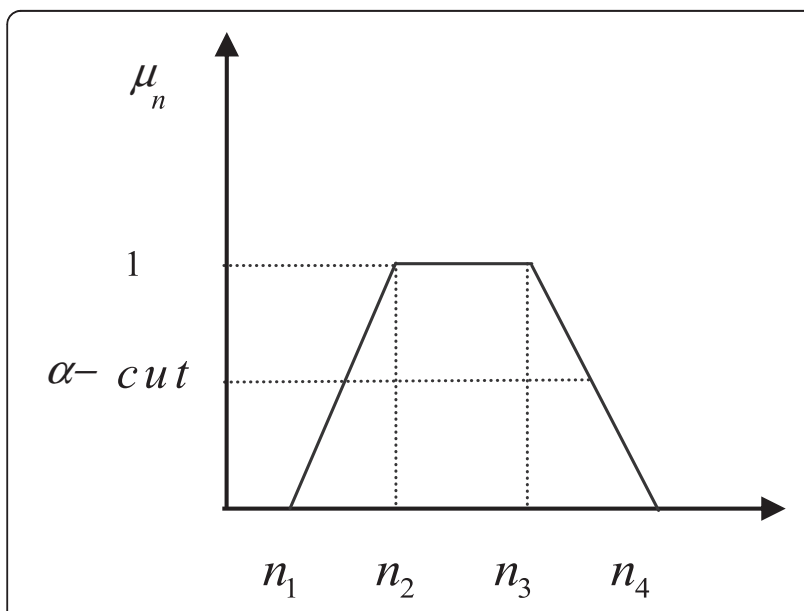

Figure 2 The membership function of trapezoidal fuzzy number $n$. demand parameter) can be transformed to their relevant crisp values due to Equations 10 to 12, respectively:

$$
\begin{aligned}
& \operatorname{MinEI}\left(\tilde{C}^{\prime}\right) x=\left[\frac{1}{2}\left(c_{1}^{\prime}+c_{2}^{\prime}\right)+\frac{1}{2}\left(c_{3}^{\prime}+c_{4}^{\prime}\right)\right] x \\
& {\left[(1-\alpha) \frac{a_{1}^{\prime \prime}+a_{2}^{\prime \prime}}{2}+\alpha \frac{a_{3}^{\prime \prime}+a_{4}^{\prime \prime}}{2}\right] x \leq \alpha \frac{b_{1}^{\prime}+b_{2}^{\prime}}{2}+(1-\alpha) \frac{b_{3}^{\prime}+b_{4}^{\prime}}{2} .} \\
& {\left[\left(1-\frac{\alpha}{2}\right) \frac{a_{1}^{\prime \prime}+a_{2}^{\prime \prime}}{2}+\frac{\alpha}{2} \frac{a_{3}^{\prime \prime}+a_{4}^{\prime \prime}}{2}\right] x \leq \frac{\alpha}{2} \frac{b_{1}^{\prime}+b_{2}^{\prime}}{2}+\left(1-\frac{\alpha}{2}\right) \frac{b_{3}^{\prime}+b_{4}^{\prime}}{2}} \\
& {\left[\left(1-\frac{\alpha}{2}\right) \frac{a_{3}^{\prime \prime}+a_{4}^{\prime \prime}}{2}+\frac{\alpha}{2} \frac{a_{1}^{\prime \prime}+a_{2}^{\prime \prime}}{2}\right] x \geq \frac{\alpha}{2} \frac{b_{3}^{\prime}+b_{4}^{\prime}}{2}+\left(1-\frac{\alpha}{2}\right) \frac{b_{1}^{\prime}+b_{2}^{\prime}}{2}}
\end{aligned}
$$

It should be noted that EI stands for the expected interval for the corresponding fuzzy number and can be computed by finding the half point of the given fuzzy number. We can therefore calculate the expected value of a triangular or any other shaped fuzzy numbers by considering the mentioned concept likewise. Equation 11 can be applied for less than or equal type constraints, and Equation 12 can be applied for the equality type constraints likewise. However, the crisp form of the proposed model can be rewritten as Equations 13 to 16 based on Equations 2, 3, 6, 7, and 8:

$$
\begin{gathered}
\sum_{p=1}^{P} \sum_{c=1}^{C} \sum_{h=1}^{H} \sum_{j=1}^{J} \mathrm{LC}_{p c h j} x_{p c h j} a_{j c}^{\prime}+ \\
\operatorname{Min}=\sum_{j=1}^{I} \sum_{c=1}^{C} \sum_{h=1}^{H} \sum_{i=1}^{I} \mathrm{LC}_{j c h i}^{\prime} y_{j c h i}\left(\frac{d_{i c h}^{1}+d_{i c h}^{2}+d_{i c h}^{3}+d_{i c h}^{4}}{4}\right) \\
+\sum_{p=1}^{P} \sum_{h=1}^{H} \mathrm{FC}_{p h} Z_{p h}+\sum_{j=1}^{J} \sum_{h=1}^{H} \mathrm{FC}_{j h}^{\prime} Z_{j h}^{\prime}
\end{gathered}
$$

S.t.:

$$
\begin{array}{r}
\mathrm{LQ}_{c h j} \leq \sum_{p=1}^{P} x_{p c h j} a_{j c}^{\prime}-\sum_{i=1}^{I} y_{j c h i}\left[\frac{\alpha}{2}\left(\frac{d_{i c h}^{1}+d_{i c h}^{2}}{2}\right)+\left(1-\frac{\alpha}{2}\right)\left(\frac{d_{i c h}^{3}+d_{i c h}^{4}}{2}\right)\right] \\
+\mathrm{LQ}_{c(h-1) ;} ; \forall c, h, i \\
\mathrm{LQ}_{c h j} \geq \sum_{p=1}^{P} x_{p c h j} a_{j c}^{\prime}-\sum_{i=1}^{I} y_{j c h i}\left[\frac{\alpha}{2}\left(\frac{d_{i c h}^{3}+d_{i c h}^{4}}{2}\right)+\left(1-\frac{\alpha}{2}\right)\left(\frac{d_{i c h}^{1}+d_{i c h}^{2}}{2}\right)\right] \\
+\mathrm{LQ}_{c(h-1) ;} ; \forall c, h, i \\
\sum_{i=1}^{I} y_{j c h i}\left[(1-\alpha)\left(\frac{d_{i c h}^{1}+d_{i c h}^{2}}{2}\right)+\alpha\left(\frac{d_{i c h}^{3}+d_{i c h}^{4}}{2}\right)\right] \leq \mathrm{LQ} \mathrm{Q}_{c h j} \quad ; \forall j, c, h
\end{array}
$$

\section{Interaction resolution method}

In this section, we explain the three levels of the resolution method in which the DM is involved interactively. 
Firstly, the linear fuzzy model transformed into its crisp mode should be solved regarding each different value of $\alpha$-cuts independently. In order to make the comparison more clearly, the solutions are compared against three quantitative measures as follows:

- Fixed cost: it can be calculated by the sum of annual fixed costs of practicing facilities in planning horizons.

- Logistics cost: it can be calculated by the sum of cost of supplying commodities from plants to customers in the given periods.

- Average customers' satisfaction: it can be determined by Equation 17 so that the average satisfied demands are determined as follows:

$$
\sum_{h=1}^{H} \frac{\left(\sum_{j=1}^{J} y_{j c h i} d_{i c h} / d_{i c h}\right)}{H} ; \forall c, i .
$$

Secondly, a decision vector should be obtained so that the DM is satisfied with respect to two conflicting factors (i.e., feasibility degree and global satisfaction). In this phase, the DM is asked to provide an aspiration level $z$ added to the relevant tolerance threshold $t$ for the values obtained by the three measures introduced above. The DM's satisfaction level can be assessed by means of a fuzzy set $\tilde{z}$ whose membership function is depicted by Equation 16 or 17 for a 'less is better' or 'much is better' case, respectively. In other words, the first two measures exemplify the 'less is better' state and the last measure typifies the 'much is better' one. However, $\lambda$ is projected in a descending and ascending manner for Equations 18 and 19, respectively:

$$
\begin{array}{rll}
1, \text { if } & \mathrm{OF} \leq z \\
\mu_{\tilde{z}}(\mathrm{OF})=\lambda \in\{0,1\} \text { if } & z \leq \mathrm{OF} \leq z+t \\
0, \text { if } & \mathrm{OF} \geq z+t \\
1, \text { if } & \mathrm{OF} \geq z \\
\mu_{\tilde{z}}(\mathrm{OF})=\lambda \in\{0,1\} \text { if } & z-t \leq \mathrm{OF} \leq z \\
0, \text { if } & \mathrm{OF}<z-t
\end{array}
$$

Since we have defined three measures $\lambda_{k}(k=1,2,3)$ for our DND problem, we are required to specify the associated weights $\omega_{k}$, with regard to the DM's opinion by one of the multi-criteria decision-making tools (e.g., AHP, ANP, or TOPSIS). At the end of the second level, the global satisfaction degree $\Omega$ can be determined by Equation 20:

$$
\Omega=\lambda_{1} \omega_{1}+\lambda_{2} \omega_{2}+\lambda_{3} \omega_{3} .
$$

Finally, we should reach a favorite balanced solution considering the feasibility degree and the global satisfaction degree at the third level. This is carried out by using
Equation 21 that consists of two fuzzy sets whose membership functions represent the magnitude the DM accepts for each feasibility degree $\rho_{\alpha}$ and satisfaction degree $\rho_{\Omega}$ importance:

$$
P=\theta \rho_{\alpha}+(1-\theta) \rho_{\Omega} \quad \text { if } \rho_{\alpha}, \rho_{\Omega} \neq 0 \text { and } 0, \text { otherwise. }
$$

Note that $P$ is the joint acceptation index obtained by the linear combination of the two mentioned degrees and $\theta \in[0,1]$ points to the relative importance the DM assigns to feasibility in comparison with global satisfaction.

\section{Computational study}

In this section, the developed fuzzy model is tested by the sensitivity analysis, and then a numerical example is solved to show its applicability and efficiency in realworld problems. Finally, the total performance of the model is investigated by different-sized problems. The calculations are run by Lingo 8 solver on a PC with characteristics of Intel $^{\circ}$, Pentium ${ }^{\circ} 4$, central processing unit (CPU) $3.20 \mathrm{GHz}$, and 2,046 MB of RAM.

\section{Sensitivity analysis}

Applying the sensitivity analysis helps us understand how accurate the problem performance is. This is demonstrated by changes in model outputs according to manipulations in parameters. In other words, it is assumed that the input data may vary independently. Hence, we have to investigate the potential changes in values of model variables. To do so, a typical example whose data have been created randomly is considered here. The results are depicted in Table 2.

\section{Implementation of interactive phases}

This section is presented in order to show how the model can be implemented with respect to the three interactive solution steps. To do so, the DM is required to specify the aspiration level of each three introduced measures $\mu \tilde{z}(\mathrm{OF})$ as follows. It should be noted that the measures' quantity is calculated according to the lower and upper bound results, obtained from different cuts:

- Fixed cost: $z=\mathrm{US} \$ 17,650,000$ and $z+t=\mathrm{US}$ $\$ 18,800,000$.

Table $\mathbf{2}$ The results of fuzzy sensitivity analysis

\begin{tabular}{lcccc}
\hline $\begin{array}{l}\text { Variation } \\
\text { source }\end{array}$ & $\begin{array}{c}\text { Fixed } \\
\text { costs } \\
\text { (US\$) }\end{array}$ & $\begin{array}{c}\text { Logistic } \\
\text { costs } \\
\text { (US\$) }\end{array}$ & OF & $\begin{array}{c}\text { Average customers' } \\
\text { satisfaction }\end{array}$ \\
\hline Fixed costs & $18,095,016$ & 947,500 & $19,042,516$ & $\mathbf{( \% )}$ \\
Logistic costs & $17,650,000$ & 765,014 & $18,415,014$ & 83.2 \\
Demand & $17,923,000$ & $1,100,540$ & $19,023,540$ & 85.7 \\
Capacities & $17,025,000$ & 945,000 & $17,970,000$ & 86.2 \\
\hline
\end{tabular}


Table 3 The comparison results between feasibility sets and deterministic state

\begin{tabular}{lcccccc}
\hline $\boldsymbol{a}$-cut & OF (US\$) & CPU time (s) & Iteration & $\begin{array}{c}\text { Fixed cost } \\
\text { (US\$) }\end{array}$ & $\begin{array}{c}\text { Logistic cost } \\
\text { (US\$) }\end{array}$ & $\begin{array}{c}\text { Average customers' } \\
\text { satisfaction (\%) }\end{array}$ \\
\hline 0 & $18,595,000$ & 14 & 52,741 & $17,650,000$ & 945,000 & 78.6 \\
0.1 & $18,602,400$ & 13 & 47,856 & $17,665,500$ & 952,400 & 81.4 \\
0.2 & $18,784,700$ & 15 & 58,996 & $17,823,000$ & 961,700 & 86.2 \\
0.3 & $18,937,300$ & 14 & 44,258 & $17,965,000$ & 972,300 & 85.7 \\
0.4 & $19,204,020$ & 21 & 68,439 & $18,220,000$ & 984,020 & 88.9 \\
0.5 & $19,558,500$ & 26 & 89,477 & $18,575,000$ & 983,500 & 94.5 \\
0.6 & $19,510,750$ & 27 & 71,644 & $18,522,000$ & 988,750 & 92.8 \\
0.7 & $19,810,600$ & 34 & 83,355 & $18,800,000$ & $1,010,600$ & 82.1 \\
0.8 & $19,844,330$ & 31 & 67,195 & $18,800,000$ & $1,044,330$ & 87.7 \\
0.9 & $19,844,050$ & 50 & 85,008 & $18,800,000$ & $1,044,050$ & 85.5 \\
1 & $19,860,010$ & 63 & 107,414 & $18,800,000$ & $1,053,070$ & 77.3 \\
Deterministic & $19,789,840$ & 19 & 104,220 & $18,800,000$ & $1,060,010$ & 81.2 \\
\hline
\end{tabular}

- Logistic cost: $z=\mathrm{US} \$ 945,000$ and $z+t=\mathrm{US}$ $\$ 1,060,010$.

- Average customers' satisfaction: $z-t=77.3 \%$ and $z=94.5 \%$.

The global satisfaction degree can be determined by weighting the measures which is done here by considering equal importance (i.e., $\omega_{1}=\omega_{2}=\omega_{3}$ ).

Afterwards, it is time to specify the joint acceptance indicator, shown by Equation 19. The results of our typical example are demonstrated in Tables 3 and 4, respectively, in which the former shows the output for each feasibility cut and the latter shows the final quantity regarding the feasibility and global satisfaction simultaneously. Note that $\theta$ is assumed to be 0.5 to give equal weights to both feasibility and global conditions.

Referring to Table 3, it can be observed that the fuzzy formulation led to lower costs for all cuts compared with the deterministic mode. However, cuts greater than 0.6 resulted in an equal value for the annual fixed cost. In

Table 4 The best cut with respect to the DM's opinion

\begin{tabular}{lllll}
\hline $\mathbf{a}$ & $\boldsymbol{\rho}_{\mathbf{a}}$ & $\boldsymbol{\Omega}$ & $\boldsymbol{\rho}_{\Omega}$ & $\boldsymbol{P}$ \\
\hline 0 & 0 & 0.02 & 0 & 0 \\
0.1 & 0.05 & 0.09 & 0.1 & 0.075 \\
0.2 & 0.15 & 0.26 & 0.33 & 0.24 \\
0.3 & 0.25 & 0.32 & 0.4 & 0.325 \\
0.4 & 0.4 & 0.47 & 0.55 & 0.475 \\
0.5 & 0.55 & 0.71 & 0.78 & 0.765 \\
0.6 & 0.7 & 0.65 & 0.7 & 0.7 \\
0.7 & 0.85 & 0.81 & 0.93 & 0.89 \\
0.8 & 0.9 & 0.82 & 0.95 & 0.925 \\
0.9 & 0.95 & 0.77 & 0.86 & 0.905 \\
1 & 1 & 0.66 & 0.72 & 0.86 \\
\hline
\end{tabular}

order to compare the results with respect to the elapsed solution time (i.e., the CPU time), it is apparent that the deterministic mode needs a rather small time although the lower cuts do the same. However, it indicates an approximately ascending order, so the last cuts required much more time that the first ones. On the other hand, the average customers' satisfaction measure showed the third lowest value for the deterministic mode. However, the measure increases as the cut magnitude goes up until it reaches the maximum value and then starts to decrease.

Considering Table 4 , it is obvious that $\alpha=0.8$ yielded the most acceptable result for the final solution. The DM's opinions can be seen for each of the different feasibility and satisfaction degrees likewise.

\section{Total performance of the model}

In order to understand the total performance of the mathematical formulation, some different-sized problems are solved and compared with respect to the elapsed solution time. The results are shown in Table 5.

\section{Table 5 The results when considering different-sized} problems

\begin{tabular}{lccccc}
\hline Problem size & $\begin{array}{c}\text { CPU } \\
\boldsymbol{p} \times \boldsymbol{c} \times \boldsymbol{j} \times \boldsymbol{i} \times \boldsymbol{h}\end{array}$ & OF (US\$) & $\begin{array}{c}\text { Average } \\
\text { customers' } \\
\text { satisfaction } \\
\mathbf{( \% )}\end{array}$ & Variables & Constraints \\
\hline $2 \times 2 \times 4 \times 6 \times 2$ & 68 & $16,855,025$ & 81 & 418 & 420 \\
$3 \times 2 \times 5 \times 8 \times 2$ & 217 & $17,120,250$ & 75 & 622 & 754 \\
$3 \times 2 \times 5 \times 9 \times 3$ & 873 & $23,864,700$ & 86 & 1,216 & 1,436 \\
$3 \times 3 \times 6 \times 9 \times 3$ & 1,307 & $25,004,610$ & 79 & 1,484 & 1,668 \\
$4 \times 3 \times 6 \times 10 \times 2$ & 4,876 & $93,324,080$ & 80 & 1,560 & 1,610 \\
$5 \times 3 \times 10 \times 12 \times 3$ & 9,654 & $26,080,950$ & 76 & 3,044 & 3,152 \\
$5 \times 4 \times 10 \times 15 \times 4$ & 14,662 & $35,775,940$ & 78 & 5,696 & 5,842 \\
\hline
\end{tabular}


It is clear that because of intrinsic intricacy, it takes a long time for the model to respond as the dimension enlarges. These problems belong to the NP-hard category, and the solution time increases exponentially as the problem size rises, in other words. For example, in Table 5, there is a noticeable difference in CPU time while even one of the problem elements changes to a higher value. This can be easily observed as the required solution time gets multi-fold once the considered problems become larger. For instance, the second problem is larger than the first one just as one unit for the number of plants and two units for the number of distribution centers, but its elapsed time is 3.19 times as much as that of the first one. Like the previous comparison, the third problem needed a more remarkable time than the second one while the number of considered customers and planning horizons has been added by one unit. That same analysis can be carried out for the rest of the problems as well. Consequently, it is suggested that intelligent computation approaches be applied for large-sized cases in particular. This makes the mathematical model be applied efficiently for any real market conditions.

\section{Conclusions}

The noticeable increase in competition amongst the market holders makes the SCM a necessary tool in fulfilling the customers' needs. DND is of great importance as it establishes the first steps in handling the network. Consequently, a multi-period, multi-commodity, multi-source DND problem was considered in this paper. We extended our formulation to an uncertain environment, due to receiving demands, by fuzzy mathematical programming. The fuzzy model consisted of a three-interaction resolution method, so it included the DMs throughout the solution procedure. Afterwards, it was validated by a sensitivity analysis, and then a numerical example was solved in order to give a picture of how the method steps can be implemented. The consideration of different-sized problems was also carried out and indicated to the intrinsic complexity.

The presented model focused on increasing the network design efficiency so that it can help more to the drawn decisions. Considering that demand uncertainty causes the disruptions, it threatens the network (e.g., the Bullwhip effect) to decrease to a great extent as the practitioners are well equipped by demand fluctuations a priori. In fact, this issue helps in the necessity of the least changes in executive plans.

For future studies, it is suggested that the presented model be solved by more effective tolls like meta-heuristic or exact methods and even compared with each other. The model can also be enriched by added concepts like the inventory control management. Furthermore, the problem can be considered by other backgrounds like economic viewpoints at the same time.

\section{Competing interests}

The authors declare that they have no competing interests.

\section{Authors' contributions}

BHT carried out the problem formulation and its solution, and JR participated in its design and coordination. Both authors read and approved the final manuscript.

\section{Acknowledgments}

We would like to express our appreciation to the University of Tehran for the financial support for this study (grant number $8108023 / 1 / 18$ ). The authors are also grateful to all persons who helped them in developing this paper.

Received: 19 March 2013 Accepted: 19 March 2013

Published: 20 May 2013

\section{References}

Altiparmak F, Gen M, Lin L, Karaoglan I (2009) A steady-state genetic algorithm for multi-product supply chain network design. Comput Ind Eng 56:521-537 Altiparmak F, Gen M, Lin L, Paksoy T (2006) A genetic algorithm approach for multi-objective optimization of supply chain networks. Comput Ind Eng $51: 196-215$

Amiri A (2006) Designing a distribution network in a supply chain system: formulation and efficient solution procedure. Eur J Oper Res 171:567-576

Azaron A, Brown KN, Tarim SA, Modarres M (2008) A multi-objective stochastic programming approach for supply chain design considering risk. Int J Prod Econ 116:129-138

Blackhurst J, Wu T, O'Grady P (2004) Network-based approach to modelling uncertainty in a supply chain. Int J Prod Res 42(8):1639-1658

Cakir O (2009) Benders decomposition applied to multi-commodity, multi-mode distribution planning. Expert Syst Appl 36(4):8212-8217

Cardona-Valdes Y, Alvarez A, Ozdemir D (2011) A bi-objective supply chain design problem with uncertainty. Transport Res C-Emer 19(5):821-832

Chen CL, Yuan TW, Lee WC (2007) Multi-criteria fuzzy optimization for locating warehouses and distribution centers in a supply chain network. J Chin Inst Chem Eng 38:393-407

Cintron A, Ravindran AR, Ventura JA (2010) Multi-criteria mathematical model for designing the distribution network of a consumer goods company. Comput Ind Eng 58(4):584-593

Georgiadis MC, Tsiakis P, Longinidis P, Sofioglou MK (2011) Optimal design of supply chain networks under uncertain transient demand variations. Omega 39(3):254-272

Goh M, Lim JYS, Meng F (2007) A stochastic model for risk management in global supply chain networks. Eur J Oper Res 182(1):164-173

Gumus AT, Guneri AF, Keles S (2009) Supply chain network design using an integrated neuro-fuzzy and MILP approach: a comparative design study. Expert Syst Appl 36(10):12570-12577

Gupta A, Maranas CD (2003) Managing demand uncertainty in supply chain planning. Comput Chem Eng 27(8-9):1219-1227

Hajiaghaei-Keshteli M (2011) The allocation of customers to potential distribution centers in supply chain networks: GA and AIA approaches. Appl Soft Comput 11(2):2069-2078

Jayaraman V, Ross A (2003) A simulated annealing methodology to distribution network design and management. Eur J Oper Res 144:629-645

Jimenez M, Arenas M, Bilbao A, Guez MV (2007) Linear programming with fuzzy parameters: an interactive method resolution. Eur J Oper Res 177:1599-1609

Jimenez M (1996) Ranking fuzzy numbers through the comparison of its expected intervals. Int J Fuzziness Knowledge-Based Syst 4(4):379-388

Liu D, Huang D, Chen Y (2006) Distribution inventory cost optimization under grey and fuzzy uncertainty. Wuhan University J Nat Sci 11(5):1238-1242

Park S, Lee T-E, Sung CS (2010) A three-level supply chain network design model with risk-pooling and lead times. Transport Res E 46(5):563-581

Peidro D, Mula J, Jimenez M, Botella MDM (2010) A fuzzy linear programming based approach for tactical supply chain planning in an uncertainty environment. Eur J Oper Res 205(1):65-80

Rezapour S, Farahani RZ (2010) Strategic design of competing centralized supply chain networks for markets with deterministic demands. Adv Eng Softw 41 (5):810-822

Rommelfanger H, Slowinski R (1998) Fuzzy linear programming with single or multiple objective functions. In: Slowinski R (ed) Fuzzy sets in decision analysis, operations research and statistics. Kluwer, Norwell, pp 179-207 
Santoso T, Ahmed S, Goetschalckx M, Shapiro A (2005) A stochastic programming approach for supply chain network design under uncertainty. Eur J Oper Res 167(1):96-115

Selim H, Ozkarahan I (2006) Application of fuzzy multi-objective programming approach to supply chain distribution network design problem. In: Gelbukh A, Reyes-Garcia CA (eds) MICAI 2006: advances in artificial intelligence. 5th Mexican international conference on artificial intelligence, Apizaco, Mexico, November 13-17, 2006 proceedings. Lecture notes in artificial intelligence (Lecture notes in computer science). Springer, Berlin, pp 415-425

Tang CS (2006) Perspectives in supply chain risk management. Int J Prod Econ 103(2):451-488

Xu J, He Y, Gen M (2009) A class of random fuzzy programming and its application to supply chain design. Comput Ind Eng 56:937-950

You F, Grossman IE (2008) Design of responsive supply chains under demand uncertainty. Comput Che Eng 32:3090-3111

doi:10.1186/2251-712X-9-13

Cite this article as: Tabrizi and Razmi: A multi-period distribution network design model under demand uncertainty. Journal of Industrial Engineering International 2013 9:13.

\section{Submit your manuscript to a SpringerOpen ${ }^{\circ}$ journal and benefit from:}

- Convenient online submission

- Rigorous peer review

- Immediate publication on acceptance

- Open access: articles freely available online

- High visibility within the field

- Retaining the copyright to your article

Submit your next manuscript at $\gg$ springeropen.com 